\title{
The use of the Mephosphon drug to accelerate the process of biogas output and ripening of organic wastes
}

\author{
Zulfiya Khaliullina ${ }^{1}$, Yuri Shogenov ${ }^{2}$, Ilnur Gayfullin ${ }^{1 *}$, Anas Mustafin ${ }^{1}$, and Insaf Nafikov ${ }^{1}$ \\ ${ }^{1}$ Kazan State Agrarian University, 420015 Kazan, Russia \\ ${ }^{2}$ Russian Academy of Sciences, 119334 Moscow, Russia
}

\begin{abstract}
This article discusses a new method for the reclamation of organic waste into biogas with the addition of the biologically active additive Mephosphon to the substrate to accelerate the process of obtaining biogas (decomposition) and preserving nutrient elements in the final product. The study object was cow manure from a private farm household. The experiments were carried out for 10 days in a lowvolume biogas unit (LVBU) without airtight in a heat-insulated reactor filled with $2 / 3$ cow manure. The use of the Mephosphon drug in ultra-low concentrations $\left(10^{-4}\right)$ allowed us to obtain a useful product in the form of high-quality organic fertilizer and biogas.
\end{abstract}

\section{Introduction}

Currently, Kazan State Agrarian University pays much attention to the issues of scientific justification of innovative technology for production [1-3] and processing [4] of agricultural products. This is especially important when developing and improving technological equipment for animal breeding.

The increase in the number of livestock complexes and private farms in connection with business development increases interest in the profitability of the recycling system and waste storage from livestock and poultry breeding. Large volumes of animal residues output and their potential hazard to natural systems in unprocessed form make it relevant to search for solutions for their disposal, reducing the hazard class of waste [5].

The approximate amount of liquid manure (t) obtained on a livestock farm or complex per day can be determined by the formula [6]:

$$
m_{m}=\sum_{i=1}^{i=m}\left(m_{e i}+m_{w i}+m_{\text {inci }}\right) \frac{n}{1000},
$$

where $\mathrm{m}_{\mathrm{ei}^{-}}$the daily output of excrements from one animal, $\mathrm{kg} ; \mathrm{m}_{\mathrm{wi}}$ - the daily amount of water added to the manure removal system per animal is taken equal to $0.2 \ldots 0.5$ - with a gravity system; $2.0 \ldots 2.5$ - with a flush system with dry cleaning of floors; 5.0...6.0 - with a flush system with floor cleaning, $\mathrm{kg} ; \mathrm{m}_{\text {inci }}{ }^{-}$the number of mechanical inclusions entering the manure removal system per day per animal of the production group is taken equal to $0.01 \ldots 0.07$ - for farms and complexes of cattle; 0.002...0.01 - for pig farms and complexes, kg; $\mathrm{n}_{\mathrm{i}}$ - the number of animals in the same production group (taken by the turnover of the herd), heads; $m$ - the number of production animals groups on the farm or complex.
The composition and properties of liquid manure depend on the diet and feeding type of animals, their species, gender and age, the technology of maintenance and feeding, economic purpose, and productivity. Liquid manure is a potential source of environmental pollution, infection of animals and people, as it contains a huge number of different microorganisms. The manure obtained from infectious animals contains pathogens of these diseases, many of which remain viable for a long time. For a long time, eggs and larvae of helminths can be preserved in the liquid manure. To environmental pollution prevention by infectious and invasive diseases, the treatment system for liquid manure on livestock farms and complexes should provide quarantine, and if necessary, disinfection and dehelminthization of liquid manure [7].

Organic waste from agricultural production is usually exported outside the farm and stored for further simple processing or natural disposal. Household waste is taken to dumps of municipal solid waste (MSW). Both lead to infection and soil acidification, making it unsuitable for cultivation without the use of expensive measures for recovery and rehabilitation. The products of rotting garbage enter the underground water, lead to emissions of greenhouse gases into the atmosphere and other negative consequences. In the case of household organic waste is solved the task of recycling by sorting and subsequent processing. In agro-industrial enterprises or farms can be waste immediately recycled. Technology implementation for non-waste production and optimization of the use of limited resources are priority tasks. Agricultural waste, which is subject to recycling, contains a significant amount of biological energybiomass. The energy potential of these wastes lies in the possibility of producing biogas from them. Biogas is a product of methane fermentation of organic waste (plant

* Corresponding author: ilnur-gai@yandex.ru 
or animal origin) and is a mixture of natural gas methane (from 55 to $85 \%$ ), carbon dioxide (from 15 to $45 \%$ ), and small amounts of hydrogen and hydrogen sulfide. The energy value of raw materials for biomethane production is determined directly by its specie [8].

One of the possible recovery processes of animal waste is anaerobic digestion with simultaneous energy production from the substrate in biogas units. The main material used as a processed substrate in biogas units is agricultural waste (manure and plant waste), industrial waste from processing enterprises.

Landfills waste and MSW dumps are processed in specialized biogas units. The waste conversion technology using a biogas unit makes it possible to obtain biogas, mineralized organic fertilizers, and vitamin feed additives for animals and birds. The main factors for the construction of biogas units are agricultural waste utilization, obtaining renewable energy (biogas, electricity), obtaining high-quality organic fertilizers, solving environmental problems. And the main argument for using biogas technologies is the promotion of nonwaste technologies in agricultural production [9].

The operation principle of biogas units is anaerobic digestion of the processed substrate, which is oxygeneliminating to the reactor. Organic waste from agriculture is fed through a specialized line to the receiver tank using scrapers or is pumped by sanitary pumps through a pipeline. The incoming organic waste in the tanks begins primary fermentation and initial preparation for loading into the reactor. The preparation consists in bringing to a certain humidity by adding liquid and stirring.

The liquid manure moisture $\mathrm{W}_{\mathrm{i}}$ can be found from the expression [10]:

$$
\mathrm{W}_{\mathrm{i}}=\frac{\mathrm{W}_{\mathrm{y}}+100 \cdot(\alpha-1)}{\alpha},
$$

where $\mathrm{W}_{\mathrm{y}}$-the excrement humidity (for cattle - $87 \%$, for pigs-87-88 \%, for sheep-74-75\%).

The amount of dry matter is calculated using the formula [11]:

$$
X=\left(\frac{C-A}{B-A}\right) \cdot 100 .
$$

The hygroscopic moisture content is determined by the formula [12]:

$$
\mathrm{W}=\left(\frac{\mathrm{B}-\mathrm{C}}{\mathrm{B}-\mathrm{A}}\right) \cdot 100,
$$

where $\mathrm{A}$ - the mass of empty sample bottle, g; B-mass of sample bottle with the initial sample of plant material, $g$; C-mass of sample bottle with the sample of plant material after drying, $\mathrm{g}$.

The prepared substrate is pumped into the reactor (the alternative name is methane digester, fermenter). The reactor must be completely sealed for full operation. It is also treated with an acid-proof and anti-corrosion coating. To maintain an even temperature are insulated the reactors. Climate conditions differ in different regions. Depending on these conditions, the insulation layer is calculated individually for each biogas unit. The materials for manufacturing reactors are steel tanks and monolithic reinforced concrete. The substrate is pumped into the reactor daily or over a specific cycle. The substrate loading dose is determined based on the fermentation time (reactor turnaround time) and the selected temperature regime. The reactor is shown schematically in figure 1.

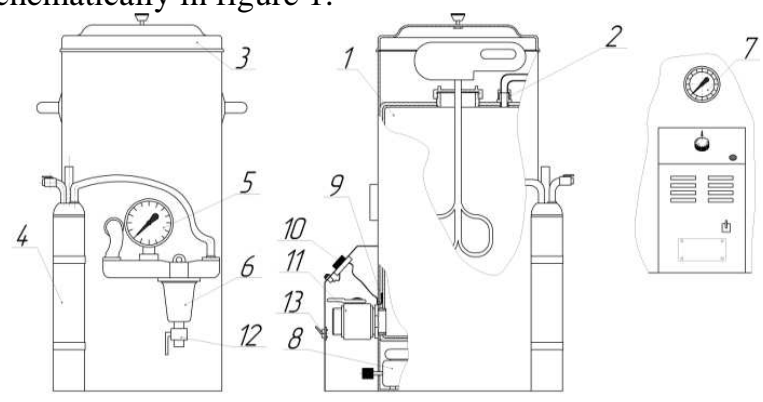

Fig. 1. Diagram of the LVBU reactor: 1-reactor; 2-agitator; 3cover; 4-small gas-holder; 5-pressure gauge; 6- filter settler; 7thermometer; 8 - electric stove; 9 - thermocouple; 10 temperature mode switch; 11 - bib cock of the substrate (biofertilizer); 12 - bib cock of the settler; 13 - power switch.

Unloading of the processed substrate (mineralized nitrogen organic fertilizers) from the reactor is similar to pumping. The work management of the entire biogas unit is controlled automatically using the software unit for limit value sensors.

A biogas unit must be maintained a certain temperature regime to increase efficiency. The basis of the energy balance of anaerobic digestion is the energy distribution in the methane digester and process heat loss. Analysis of published data on the energy expenditure of the anaerobic digestion process [13, 14] showed that the main heat load falls on heating the fresh substrate to the fermentation temperature. The heat energy distribution for the anaerobic digestion process is shown in table 1 .

Table 1. The heat energy distribution for the anaerobic digestion process.

\begin{tabular}{|l|l|}
\hline Process & $\%$ \\
\hline Heating the substrate & 72 \\
\hline $\begin{array}{l}\text { The temperature losses compensation } \\
\text { through the filler structure of the bioreactor }\end{array}$ & 14.1 \\
\hline Process loss compensation & 13.9 \\
\hline
\end{tabular}

The temperature regime is the main condition for life support of microorganisms and the microflora state.

Three temperature regimes are known: butterflypollinated (operational temperature ranging from 15 to $25{ }^{\circ} \mathrm{C}$ ); mesophilic (operational temperature from 26 to $45^{\circ} \mathrm{C}$ ); thermophilic (operational temperature from 46 to $\left.55^{\circ} \mathrm{C}\right)$ [15].

To evenly distribute the maintained temperature and destroy the resulting substrate crust. The substrate is mixed inside the reactor. Mixing takes place using submersible mixers, and in some cases air-driver agitators. Biogas is pumped automatically using a compressor through a pipeline to the gas-holder. For safe operation of the biogas unit are installed in it a condensate drainage device and a safety valve. The valve is installed to protect the gas-holder from exceeding the permissible pressure. Limit value sensors enable the safe operation of the biogas unit. The operation system of the 
biogas unit can also be started in a manual run. Biogas units can operate for up to 20 years without breakdowns.

The study's purpose is to accelerate the process of biogas release and preserve nutrient elements in processed biomass.

The research objectives are: To study the effect of the drug Mephosphon on the output of biogas and to study the physical and chemical characteristics of fermented biomass.

\section{Materials and methods}

The main results of the work are obtained based on theoretical and experimental studies. The study was conducted in a low-volume biogas unit developed at the Kazan State Agrarian University.

The LVBU construction (Fig. 2.) is a bioreactor with a volume of 30 liters, in which the processed bioenergy substrate is placed in certain ratios. The produced biogas is fixed by a household gas meter. And the pressure is controlled by an electric-contact pressure gauge. The biogas burns with a blue flame, and the combustion takes place by feeding the biogas to the burner. The elements of a low-volume biogas unit are a compressor, an electric stove, a programmer, a temperature controller, and a control panel [16].

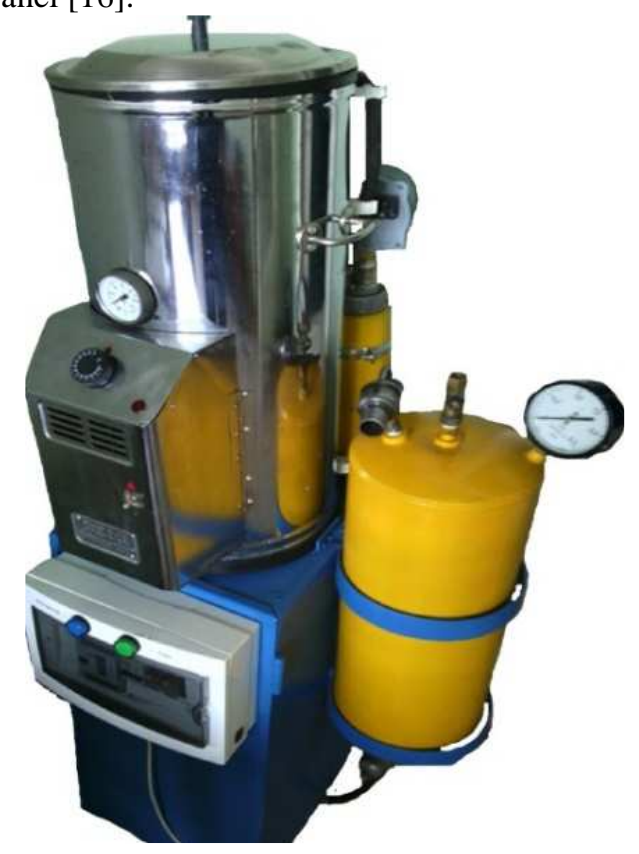

Fig. 2. Low-volume biogas unit

To launch the LVBU, follow these steps. Before starting the experiment is prepared the substrate for loading into the bioreactor. The first experiment (variant No.1) was conducted using fresh cow excrement at a humidity of up to $90 \%$. At this humidity, the substrate will have good fluidity, which facilitates the loading operation into the reactor. For example, the humidity of fresh cattle manure was 85-86\%. To create the necessary humidity of $90 \%$, fresh manure was diluted with warm water at a temperature of $80{ }^{\circ} \mathrm{C}$. At the same time, water was preliminarily settled. A generally accepted method was used [17]. Determination of the hygroscopic moisture content is based on taking into account changes in the mass of air-dry material when drying it in a thermostat at a temperature of $100-105^{\circ} \mathrm{C}$ to constant weight. Empty dried weighing bottles were weighed on the scales and their weights were recorded $\left(\mathrm{M}_{0 \mathrm{i}}\right)$. Then the same weighing bottles with biomass were weighed and their weights recorded ( $\left.\mathrm{M}_{\text {biomass.i }}\right)$. After fixing the masses were installed open weighing bottles with biomass samples in the drying cabinet. The samples were kept in a drying cabinet for 8 hours at a temperature of $105^{\circ} \mathrm{C}$. They closed the weighing bottles with ground stopper, transferred them to the drying cabinet, and kept there until completely cooled (about 40 minutes). Weighed weighing bottles with the biomass of absolutely dry samples and recorded their mass $\left(\mathrm{M}_{\text {abs.dry.i }}\right)$. From the obtained mass determinations, the substrate humidity was found, and then, taking into account this humidity, the substrate was selected for loading into the bioreactor.

The prepared substrate was loaded into the bioreactor. The substrate was stirred periodically throughout the cycle using an electric agitator. Biogas was accumulated in the reactor initially. Further, the accumulated biogas in the reactor, passing through the hydraulic lock, entered the small gas holder and, displacing water, accumulated in it. The hydraulic lock prevents the reverse penetration of biogas into the bioreactor. The resulting biogas is pumped from the small gas holder forcibly, using a compressor, to the gas holder (gas storage). The gas holder has an output valve to ensure safe operation. The organic fertilizer removal is carried out through the draining cock on the tank.

\section{Results and Discussion}

To identify the effect of the drug Mephosphon on the output of biogas and the production of organic fertilizers, a second experiment was performed (variant No 2). They also took the excrements of the same cows with the addition of the drug Mephosphon. The effect of the drug Mephosphon on the process of anaerobic digestion of cow excrement from a subsidiary personal farm was studied at a concentration of $10^{-4} \mathrm{~g} / \mathrm{l}$. The introduced drug doses were determined according to the Technology regulations and according to the results of preliminary experiments in the laboratory of the Kazan State Agrarian University [18]. During the tests, the temperature regulation of the substrate was monitored, the smell level of the tested substrate was determined, the initial and final humidity of cow excrement, as well as the presence of pathogenic microflora in the resulting product. Both studies were carried out in a thermophilic fermentation mode with an operating temperature of 55 ${ }^{\circ} \mathrm{C}$ using the following substrates: experiment 1 , cow excrement 201 (humidity 84.4\%); experiment 2, cow excrement 201 (humidity $85 \%$ ) with the addition of $10^{-4}$ $\mathrm{g} / \mathrm{l}$ of the drug Mephosphon. In this technological process, under the thermophilic fermentation mode was kept the substrate in the bioreactor under anaerobic conditions (airtight) for 10 days. And when the preparation Mephosphon was added, the substrate was kept in the bioreactor for 7 days. 
The experiment results are shown in figure 3.

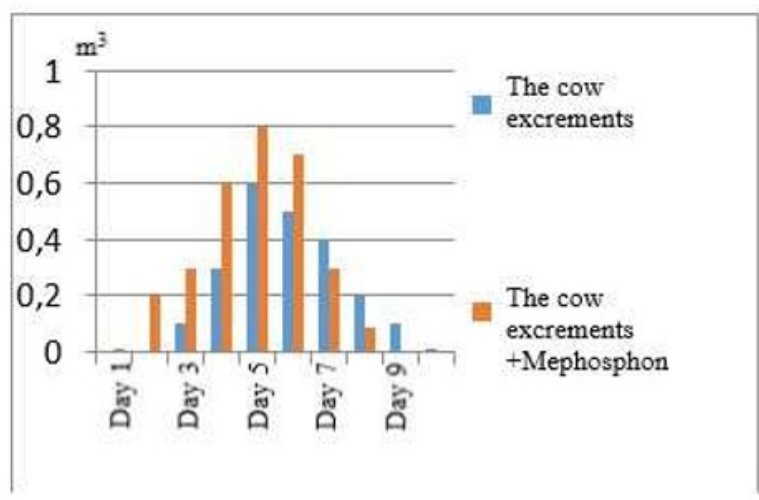

Fig. 3. Kinetics of biogas formation

Based on the test results, it can be noted that the biogas released without the addition of the drug Mephosphon begins on average on 2 - 3 days, and when it is added to the substrate, the release begins on 1-2 days. This depends on the original substrate composition, on the ratio of proteins, fats, and carbohydrates contained in the substrate.

Diagram analysis (Fig. 3.) shows that the maximum biogas yield is $0.8 \mathrm{~m}^{3}$ in the substrate with the preparation Mephosphon, the gas release is observed for up to 7 days. The methane content $\left(\mathrm{CH}_{4}\right)$ is about $65 \%$.

"STATISTICA" program provides graphical images of response surfaces that reflect the relationship between the optimization criterion and two independent variables.

Figure 4 shows a graphical image of the response surfaces.

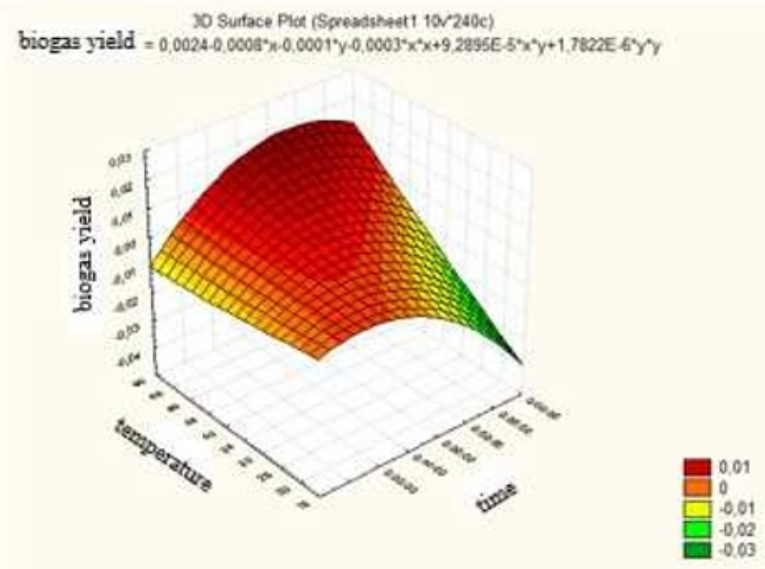

Fig. 4. Biogas output dependence on time and temperature change

It is convenient for the response surfaces to analyze using equal output lines (isolines). They are shown in figure 5. Considering all possible isolines gives a clear idea of the values of the optimization criterion that it will take when varying the levels of each pair of factors. Analyzing figure 4, we see that at the fixed zero level of the parameter $\mathrm{X}_{1}$ (temperature), the optimum region is within the range of $\mathrm{K}=0.16-0.18 \%$.

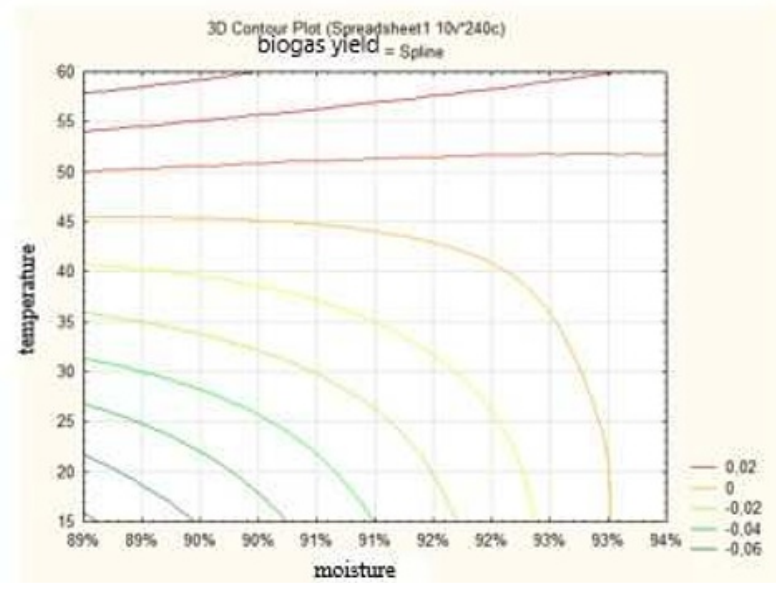

Fig. 5. Biogas output dependence on temperature and substrate humidity. A set of equal output lines (isolines)

After decoding the factors, the object model in physical quantities takes the form:

$\mathrm{Y}=0,0024-0,008 \mathrm{~T}+0,06525 \tau-0,0003 v+9,2895 \mathrm{~K}-$

$0,00118 \mathrm{~T} \tau-0,8437 \tau \mathrm{K} 0,24375 v \mathrm{~K}$,

where $\mathrm{T}$ is the temperature- $53.9^{\circ} \mathrm{C}$; $\tau$ is the isothermal cycle duration -168 hours; $\mathrm{K}$ is the concentration, 0.18 $\%$.

Mathematical modeling of the anaerobic digestion process of organic waste in biogas units is important. A Mono model describing the process of anaerobic digestion of organic waste depending on the specific growth rate of microorganisms is presented [19]:

$$
\mu=\mu_{M} \frac{S}{K_{S}+S}
$$

where $\mu_{M}$-the maximum specific growth rate of microorganisms, day ${ }^{-1} ; K_{s}$ - the Mono constant, at which the growth rate is 0.5 maximum.

The reactor has a unique fermentation process (processing of cow excrement with the help of bacteria). When added to a substrate of the preparation Mephosphon increases the biomass concentration of these bacteria and their metabolic products. Organic fertilizer processed in LVBU acquires new properties. It contains all the components (amino acids, phosphorus, nitrogen, potassium, macro - and microelements) that contribute to the normal growth and development of the plant. When applying bioorganic fertilizer to the soil, anaerobic bacteria promote nitrogen fixation and ammonification, thereby helping plants to assimilate nitrogen. All this improves the composition and structure of the soil, increases crop yields, and reduces the maturation time. [19]:

The nitrogen balance is calculated using the equation

$$
B_{N}=\left(N_{f}+N_{s}+N_{b}+N_{v r}+N_{p r e}\right)-\left(N_{v}+N_{v r}+N_{n}\right)
$$
where, $N_{f}$ - income with biofertilizers $N_{f}=\left(N_{m}+N_{\text {org }}\right), N_{m}$ - income with mineral fertilizers; $N_{\text {org }}$ - income with organic fertilizers; $N_{s}$ - income with seeds; $N_{b}$ - income from biological fixation; $N_{b}=\left(N_{\text {sym }}+N_{n s y m}\right) ; N_{\text {sym }}$ - income from symbiotic fixation; $N_{n s y m}$ - income from fixation by free-living microorganisms; $N_{v r^{-}}$income with vegetable remains; $N_{p r e}$ income with atmospheric precipitation. 
The effect of biofertilizers on plants begins immediately after applying it to the soil. This fertilizer can be used all year round for house and ornamental plants. The use of biofertilizers in the cultivation of potatoes, cabbage, beets, carrots, eggplants, tomatoes, pumpkins, raspberries, currants, and other vegetables and berries, as well as legumes, fodder and lawn grasses, gives a heavy crop. It has a very good effect on the flowering of decorative flowers, such as roses, daffodils, asters, etc.

The conducted microbiological analysis of the experiments showed that in the experiment with the preparation Mephosphon use (variant No. 2), the content of enterococcus and coliform bacteria was lower than in the experiment without the preparation Mephosphon (variant No. 1).

The preparation Mephosphon reduces the time of maturation and neutralization of agricultural waste, which indicates the prospects of its use. After processing waste in a biogas unit, they are free of pathogenic microflora, worm eggs, weed seeds, nitrites, and nitrates [20].

Analysis of toxicological characteristics of cow excrement samples showed that processing it in a biogas unit by the end of the fermentation cycle leads to a decrease in the toxicity of the samples under study. The results of the toxicity study are shown in table 2 .

Table 2. Changes in the toxic properties of cow excrement during the experiment.

\begin{tabular}{|l|c|c|c|c|}
\hline \multirow{2}{*}{$\begin{array}{l}\text { Experim } \\
\text { ents } \\
\text { variant }\end{array}$} & \multicolumn{4}{|c|}{ Toxicity, $\left(\mathrm{Kp}_{10}\right)^{*}$} \\
\cline { 2 - 5 } & $\begin{array}{c}\text { Initial } \\
\text { P. } \\
\text { caudatum }\end{array}$ & $\begin{array}{c}\text { C. } \\
\text { Affinis }\end{array}$ & $\begin{array}{c}\text { P. } \\
\text { P. } \\
\text { caudatum }\end{array}$ & $\begin{array}{c}\text { C. } \\
\text { affinis }\end{array}$ \\
\hline \multicolumn{5}{|c|}{ Cow excrement from a private farm } \\
\hline \multirow{2}{*}{ No.1 } & 40 & 215 & 25 & 62 \\
\hline \multirow{2}{*}{ No.2 } & & & 25 & 39 \\
\hline
\end{tabular}

* $\mathrm{Kp}{ }_{10}$ is a reciprocal dilution of aqueous extract from the substrate, which eliminates its harmful effects on hydrobionts.

During further incubation without external intervention, the toxicity of all substrate samples concerning Ceriodaphnia affinis practically did not change and concerning Paramecium caudatum decreased by 1.5 times.

It should be noted that the final nitrogen content in the treated substrate is higher than in the untreated substrate. The acidity values in the substrate are $\mathrm{pH} 6.7$ in the untreated and 7.5 in the treated substrate. This indicates the most profound metabolism of organic acids in the last and most active functioning of spore-forming organisms and actinomycetes.

It also contributes to a more complete breakdown of proteins, the ammonia release, and medium alkalization to optimal values. It is recommended to use the resulting product on acidic soils. The content of phosphates $\left(\mathrm{P}_{2} \mathrm{O}_{5}\right.$ $-1.4-1.5 \%)$ and potassium $\left(\mathrm{K}_{2} \mathrm{O}-1.0-1.1 \%\right)$ in both samples of fertilizers after treatment in a biogas unit did not differ significantly.

\section{Conclusion}

Thus, during processing and fermentation in a biogas unit of cow excrement, a biofertilizer was obtained that meets the physical and chemical and sanitary and biological characteristics of the requirements of All-Union State Standard R53117-2008 "Organic fertilizers based on animal waste".

\section{References}

1. I. Maksimov, N. Adigamov, A. Mustafin, D. Khaliullin, I. Gayaziev, A. Matyashin, R. Lukmanov, Theoretical fundamentals for determining soil erosion potential (energy concept) Part 1, Periodico tche Quimica, 16(31), 540-557 (2019).

2. A. Belinsky, B. Ziganshin, A. Valiev, D. Haliullin, I. Galiev, N. Adigamov, Theoretical investigation of increasing efficiency of combine harvester operation on slopes, Engineering for Rural Development, 18, 206-213 (2019) doi: 10.22616/ERDev2019.18.N252

3. R. Sabirov, A. Valiev, L. Karimova, A. Dmitriev, D. Khaliullin, Influence of physical factors on viability of microorganisms for plant protection, Engineering for Rural Development, 18 (2019) 10.22616/ERDev2019.18.N211

4. R. Ibyatov, A. Dmitriev, B. Ziganshin, D. Khaliullin, A. Zinnatullina, Mathematical modeling of the grain trajectory in the workspace of the sheller with rotating decks, BIO Web. Conf., 17, 00093 (2020). DOI: 10.1051/bioconf/20201700093

5. B. G. Ziganshin, Yu. Kh. Shogenov, I. Kh. Gayfullin, I. I. Kashapov et al., Modern energysaving solutions in agriculture (Kazan State Agrarian University, Kazan, 2018) 237 p.

6. C.A. Pierce, R.J. Smernik, T.M. Mc Beath, Phosporous availability in chicken manure lower with increased stockpiling period, despite a lager orthophosphate content, Plant and Soil, 373(1-2), 359-372 (2013)

7. A. Sun, W. Cao, C.J. Banks, S. Heaven, R. Liu, Biogas production from undiluted chicken manure and maize silage: a study of ammonia inhibition in high solids anaerobic digestion, Bioresour. Technol., 218, 1215-1223 (2016)

8. S. Sakar, K. Yetilmezsoy, E. Kocak, Anaerobic digestion technology in poultry and livestock waste treatment - a literature review, Waste Management \& Research, 27(1), 3-18 (2009)

9. D.Y. Suslov, P.S. Sedyh, Experimental studies of the process of obtaining biogas from wastes from 
agricultural enterprises, In: International Science and Technology Conference "EastConf", 8725328 (2019)

10. V. Petric, Selimbasic, Composting of poultry manure and wheat strew in closed reactor: optimum mixture ratio and evplotion of parameters, Biodegradation, 11, 53-63 (2006)

11. D.E. Belostotskiy, V.A. Miluykov, E.E. Ziganshina, A.M. Ziganshin, M. Siniagina, E.A. Boulygina, Impact of the substrate loading regime and phosphoric acid supplementation on performance of biogas reactors and microbial community dynamics during anaerobic digestion of chicken wastes, Bioresource Technology, 193, 42-52 (2015)

12. N.I. Seomushkin, B.G. Ziganshin, S.M. Yakhin, B.A. Gayfullin, R.E. Vlasov, Mathematical model of interaction of seeds with the internal surface of sowing block of seed drill, Journal of Research in Science Teaching, 531, 531 (2012)

13. A. Makkar, C. Parkash, J. Singh, Vermicompost and vermiwash as supplement to improve seedling, plant growth and yield in linum usitassimum $l$. For organic agriculture, International Journal of Recycling of Organic Waste in Agriculture, 6(3), 203-218 (2017)

14. E.E. Ziganshina, E.M. Ibragimov, P.Y. Vankov, A.M. Ziganshin, V.A. Miluykov, Comparison of anaerobic digestion strategies of nitrogen-rich substrates: performance of anaerobic reactors and microbial community diversity, Waste Management, 59, 160-171 (2017)

15. Q. Zhang, J. Hu, D.J. Lee, Biogas from anaerobic digestion processes: research updates, Renewable Energy, 98, 108-119 (2016)

16. A.P. Akimov, Y.V. Konstantinov, V.I. Medvedev, B.G. Ziganshin, Application of kinematic analysis in rational selection of parameters and operation modes, Opcion, 34(Special Issue 17), 384-400 (2018)

17. F.S. Sibagatullin, Z.M. Khaliullina, A.M. Petrov, K.O. Sinyashin, The prospects of using various commercial formulations to accelerate the process of "maturation" of chicken manure, Bulletin of Kazan State Agrarian University, 14, 1(52), 53-57 (2019)

18. Process regulations "Reducing the hazard class (neutralization) of animal waste with the use of a biologically-active preparation - "Mephosphon" (Approved by the State Duma Deputy of the Russian Federation) (Kazan, 2017)

19. L. Xue, P. Zhang, H. Shu, C. Chang, R. Wang, S. Zhang, Agricultural waste, Water Environment Research, 88(10), 1334-1373 (2016)

20. F.S. Sibagatullin, Z.M. Khaliullina, A.R. Safiullina et al., Fermentation processes studying of chicken manure under the influence of a biologically active supplement "Mephosphon", Bulletin of Kazan State Agrarian University, 2(49), 42-47 (2018) 